\title{
Perceived Trauma and Mental Health among Refugees in India
}

\author{
Akbar Hussain, Monu Lal Sharma
}

Department of Psychology, Jamia Millia Islamia, India

Copyright $@ 2015$ Horizon Research Publishing All rights reserved.

\begin{abstract}
Refugees who leave their country because of fear of violence or starvation usually had extreme traumatic experiences which affect their mental health immensely. Since limited researches are available on the psychological problems of refugees present study attempted to assess the traumatic experiences and mental health status of refugees. The study was conducted on 60 refugees from Myanmar staying in India for the last three years. To assess the extent of their traumatic experiences post-traumatic stress disorder checklist was used. Besides that a Brief Psychiatric Rating Scale was also administered to assess their mental health status. Findings showed substantial traumatic experience and poor mental health of the refugees in general. Significant difference between males and females were obtained in traumatic experiences and status of mental health. However, mixed results were obtained for the two age groups of both the genders on traumatic experience and mental health. Further, significant correlations were also found between the two variables.
\end{abstract}

Keywords Refugee, Traumatic Experience, Mental Health, Post- traumatic Stress

\section{Background}

India offers shelter to a substantial number of refugees from different nations, although India is not signatories of the 1951 Refugee Convention. Most of the time, life security is the main reason behind leaving their homes, but in other cases due to nonfulfillment of the basic needs, which varied according to their identity and location they flee from the own country. Perceived traumatic experiences by the refugees in their country of origin and post migration distress, cultural differences and language barrier affect their mental health in country of asylum. Earlier researches has shown that historical factors, such as degree of trauma exposure (Heptinstall, Sethna, \& Taylor, [7]; Mollica, Poole, Son, Murray, \& Tor, [18]; Papageorgiou, Frangou-Gurunovic, Ioradanidour, Yule, Smith \& Vostanis [21]; Rousseau
\&Drapeau, [3]; Sack, Clarke, \& Seeley, [22], fleeing without parents, immigrating at an older age (Halcon, Robertson, Savik, Johnson, Spring, Butcher, et al., [15], are related to higher levels of post-traumatic stress disorder (PTSD), relatively little is known about what post-resettlement factors are associated with mental health problems in refugee youths.

Refugee experiences some form of traumatic experience and most of them are victims of war \& conflict, physical and/or sexual abuse. Traumatic experiences can have a devastating impact on their physical, emotional, cognitive and social development. Traumatic events increase the risk poor mental health. Stern [4] suggested that current or recent trauma may affect an individual's assessment of the more distant past, changing the experience of the past and resulting in dissociative states. A review of factors that influence the risk for the common mental disorders proposed trauma as a shared risk factor, Ormel, Jeronimus, Kotov, Riese, Bos \& Hankin [10] and Malouff, Thorsteinsson, \& Schutte [13].

Refugees perceive extensive trauma while migrating from country of origin to asylum. Burmese refugees taking shelter in neighbour countries namely Nepal, India, Thailand etc. continuous exposures of traumatic events affected their mental health. Some studies suggested that refugees often develop Post Traumatic Stress Disorder or Acute Stress Disorder, which negatively effects their adjustment to life in a new country (Lacroix \& Sabbah [17]). Traumas and stressors faced by refugees during their physical and psychological odyssey, they have been found to generally be at high risk for mental health problems (Keyes [8]).

Refugees in India from Burma, like many other refugees' experienced traumatic events but their psychosocial difficulties were not sufficiently been considered or understood. Keeping in the view the limited literature on perceived trauma and metal health of refugees, the present study was undertaken to examine the level of perceived trauma and mental health among male and female refugees of Myanmar. The following hypotheses were formulated in the light of available literature:

1. There would be difference between male and female refugees on the perceived trauma scores. 
2. There would be difference between the refugees of two different age groups on their perceived traumatic experience.

3. There would be significant difference between male and female refugees on the mental health status.

4. There would be difference between the refugees of two different age groups on the mental health status.

5. There would be inverse relationship between traumatic experience and the mental health status of the refugees.

\section{Method}

Present study was conducted on sixty male and female refugees originally belonging to Myanmar but settled in Delhi for the last three years. Out of total 60 participants 23 were female participants and remaining 37 were male refugees. The participants were belongs to different age ranging from $21-55$ years. They were classified into two groups i.e. $21-35$ yrs. and 35 - 50 yrs. All the participants were taken from different localities of Delhi where they were residing for more than three years. Most of them were not having formal education.

\section{Measures}

The Posttraumatic Stress Disorder Checklist (PCL) by Weathers, Litz, Herman, Huska \& Keane [9] was administered for assessing the extent of traumatic experiences perceived by the refugees. The internal consistency of the tool was very high for all the 17-item scale.

A Brief Psychiatric Rating Scale (BPRS) developed by Overall and Gorham [11] was also used to assess mental health status of the participants. The scale consisted of 18 items on seven point scale $(1=$ not present, $7=$ most severe). Higher score on scale indicate poor mental health. Validity of the two tools was also reported very high.

\section{Procedure}

Since the participants were not educated but they were knowing Hindi language to some extent. However, in the data collection process services of interpreter was taken. The participants were informed about the purpose of visit and their verbal consent was sought. Both the measures were administered on the identified refugees in individual setting. The duration of each administration continued for approximately 30 minutes. The obtained data were analysed with the help of non-parametric statistical techniques as the data were not normally distributed because of purposive sampling.

\section{Results}

The obtained data were arranged and categorized into two different age groups for separately for male and female. Since the data were non-normal non-parametric statistics were used. The data were analysed with the help of median, Inter quartile range\& Mann-Whitney U-tests whereas for examining the relationship between the variables spearman's correlation coefficient was computed and the results were presented in the following tables.

Table 1. Median and inter quartile range of perceived trauma scores of male and female refugees and ' $u$ ' value for the difference between the two groups.

\begin{tabular}{|c|c|c|c|c|c|}
\hline Group & $\mathrm{N}$ & Median & $\begin{array}{c}\text { Inter quartile } \\
\text { Range }\end{array}$ & $\mathrm{U}$ & $\mathrm{Z}$ \\
\hline Male & 37 & 60.00 & 16.50 & & \\
\hline Female & 23 & 63.00 & 16.00 & 379.0 & .708 \\
\hline
\end{tabular}

${ }^{* *} \mathrm{p}<.01,{ }^{*} \mathrm{p}<.05$

The above result showed that male and female refugees both had substantial traumatic experiences in general. As such no significant difference between the male and female refugees were obtained on the traumatic experience scores $(\mathrm{U}=379.00$ and $\mathrm{Z}=.708)$. Median value for male participants was found 60.00 and IQR was found 16.50 whereas for the females refugees' median value was found 63.00 and IQR was found 16.00. Thus females had an edge over the males on the intensity of traumatic - experiences. Therefore, it can be said that gender variation had no role in the perception of traumatic events. In this way hypothesis I presuming difference between male and female refugees on perception of traumatic experiences could not be confirmed completely.

Table 2. Median and inter quartile range of perceived trauma scores of male refugees of two different age groups and ' $u$ ' value for the difference between the two groups.

\begin{tabular}{|c|c|c|c|c|c|}
\hline Age Group & $\mathrm{N}$ & Median & $\begin{array}{c}\text { Inter quartile } \\
\text { Range }\end{array}$ & $\mathrm{U}$ & $\mathrm{Z}$ \\
\hline $21-35$ yrs. & 11 & 65.00 & 11.00 & & \\
\hline $36-55$ yrs. & 26 & 57.00 & 16.25 & 81.50 & $2.04 * *$ \\
\hline
\end{tabular}

$* * \mathrm{p}<.01, * \mathrm{p}<.05$

The above results showed that male refugees of two different age groups were suffering from substantial trauma in general, the difference between the two groups on the scores of traumatic experience was also found significant $(\mathrm{U}=81.50$ and $\mathrm{Z}=2.04)$. Group I (21-35 yrs.) perceived traumatic experience with much higher intensity than group II (36 -55 yrs.). As the median of group I (21-35 yrs.) was found 65.00 and IQR was found 11.00 whereas the group II (36-55 yrs.) median was found 57.00 and IQR was found 16.25. Thus, it can be said that age has inevitable role in perception of traumatic experiences. Thus, it was obvious that younger refugees were more prone to traumatic experiences. 
Table 3. Median and inter quartile range of perceived trauma scores of female refugees belonging to two different age groups and ' $u$ ' value for the difference between the two age groups.

\begin{tabular}{|c|c|c|c|c|c|}
\hline $\begin{array}{c}\text { Age } \\
\text { Group }\end{array}$ & $\mathrm{N}$ & Median & $\begin{array}{c}\text { Inter quartile } \\
\text { Range }\end{array}$ & $\mathrm{U}$ & $\mathrm{Z}$ \\
\hline $\begin{array}{c}21-35 \\
\text { yrs. }\end{array}$ & 14 & 68.00 & 18.50 & & \\
\hline $\begin{array}{c}36-55 \\
\text { yrs. }\end{array}$ & 9 & 56.00 & 12.50 & 38.50 & $1.54^{*}$ \\
\hline
\end{tabular}

$* * \mathrm{p}<.01, * \mathrm{p}<.05$

The above results showed that female refugees of two different age groups (21-35 yrs. and 36-55 yrs.) perceived traumatic experiences substantially, however the difference between the two age groups on the scores of traumatic experience was also found significant ( $\mathrm{U}=38.50$ and $\mathrm{Z}=$ 1.54). Group I showed perception of trauma with much intensity than the group II. As the median of group I (21-35 yrs.) was found 68.00 and IQ 18.00 whereas the group II (36-55 yrs.) median was found to be 56.00 with IQR of 12.50 . Thus age variations play vital role in the perception of traumatic experiences for males and females both. In general results revealed that younger refugees were more vulnerable to traumatic experiences.

On the basis of above results given in the tables $2 \& 3$ hypothesis II presuming differences between the refugees of two age groups on the perception of traumatic-experience was found confirmed.

Table 4. Median and inter quartile range of mental health scores of male and female refugees and ' $u$ ' value for the difference between the two groups.

\begin{tabular}{|c|c|c|c|c|c|}
\hline Group & $\mathrm{N}$ & Median & $\begin{array}{c}\text { Inter quartile } \\
\text { Range }\end{array}$ & $\mathrm{U}$ & $\mathrm{Z}$ \\
\hline Male & 37 & 59.00 & 6.00 & \multirow{2}{*}{309.0} & \multirow{2}{*}{1.77} \\
\hline Female & 23 & 57.00 & 5.00 & & \\
\hline
\end{tabular}

${ }^{* *} \mathrm{p}<.01,{ }^{*} \mathrm{p}<.05$

The above result showed that the mental health of male and female refugees' were poor in general and there was no significant difference between the male and female refugees on the mental health scores ( $U=309.00$ and $Z=1.77$ ). There was marginal difference between the two groups on the mental health status as the median value for male participants was found 59.00 and IQR was found 6.00 whereas for the female participants it was found 57.00 and IQ 5.00. Despite of marginal gender differences, male had an edge over the females on the status of mental health. Thus, it can be said that gender had no significant role in the maintaining mental health among refugees. In this way hypothesis III presuming difference between male and female refugees on mental health could not be confirmed completely.
Table 5. Median and inter quartile range of mental health scores of male refugees belonging to two different age groups and ' $u$ ' value for the difference between the two groups.

\begin{tabular}{|c|c|c|c|c|c|}
\hline $\begin{array}{c}\text { Age } \\
\text { Group }\end{array}$ & $\mathrm{N}$ & Median & $\begin{array}{c}\text { Inter quartile } \\
\text { Range }\end{array}$ & $\mathrm{U}$ & $\mathrm{Z}$ \\
\hline $\begin{array}{c}21-35 \\
\text { yrs. }\end{array}$ & 11 & 64.00 & 6.00 & \multirow{2}{*}{74.00} & $2.31^{*}$ \\
\hline $\begin{array}{c}36-55 \\
\text { yrs. }\end{array}$ & 26 & 59.00 & 3.25 & & \\
\hline
\end{tabular}

${ }^{* *} \mathrm{p}<.01,{ }^{*} \mathrm{p}<.05$

The above results showed that male refugees of two different age groups were suffering from mental health problem in general, however the difference between two age groups (21 -35 yrs. \& 36-55 yrs.) on the scores of mental health was also found significant $(\mathrm{U}=74.00$ and $\mathrm{Z}=2.31$ ). From the result it was obvious that group I had much poor mental health than the group II. As the median of group I (21-35 yrs.) was found 64.00 and IQR 6.00 whereas for the group II (36 -55 yrs.) median was found 59.00 and IQR 3.25. Besides the gender variation age was also crucial for the mental health. Younger male refugees were more vulnerable to mental health related problems than older.

Table 6. Median and inter quartile range of perceived trauma scores of female refugees of two different age groups and ' $u$ ' value for the difference between the two groups.

\begin{tabular}{|c|c|c|c|c|c|}
\hline $\begin{array}{c}\text { Age } \\
\text { Group }\end{array}$ & $\mathrm{N}$ & Median & $\begin{array}{c}\text { Inter quartile } \\
\text { Range }\end{array}$ & $\mathrm{U}$ & $\mathrm{Z}$ \\
\hline $\begin{array}{c}21-35 \\
\text { yrs. }\end{array}$ & 14 & 58.00 & 6.00 & & \\
\hline $\begin{array}{c}36-55 \\
\text { yrs. }\end{array}$ & 9 & 56.00 & 5.50 & 56.50 & .41 \\
\hline
\end{tabular}

$* * \mathrm{p}<.01, * \mathrm{p}<.05$

Significance of age was not obvious in the above results that showing female refugees of two different age groups (21-35 yrs. and 36- 55 yrs.) were having poor mental health in general but the difference between two age groups on the score of mental health was also not found significant $(\mathrm{U}=56.50$ and $\mathrm{Z}=.41)$. Result showed that there was no difference between the two age groups of refugees on their mental health status. The median of group I (21-35 yrs.) was found 58.00 and IQR 6.00 whereas the group II (36 -55 yrs.) median was found 56.00 and IQR 5.50. Though group 1 was suffering from mental health problem little higher than group 11 but the difference was not significant. Thus mental health related issues can be occurred at any stage of life especially in women.

On the basis of results of above tables $(5 \& 6)$ the hypothesis IV presuming differences in two age groups of refugees on mental health was found partially confirmed. 
Table 7. Spearman's rank difference correlation between scores of traumatic experience and mental health among refugees $(n=60)$.

\begin{tabular}{|c|c|}
\hline Variables & Mental Health \\
\hline Perceived Trauma & $.565^{* *}$ \\
\hline
\end{tabular}

$* * \mathrm{p}<.01, * \mathrm{p}<.05$

It was apparent from the results presented in the above table that the overall relationship between the two variables namely perceived trauma and mental health was significant as $\rho=.565$. Since higher score on mental health indicates poor mental health status direct relationship between the two scores showing in fact inverse relation between the variables. Thus it can be said that traumatic experience and mental health were going opposite to each other. It can be said that traumatic experiences producing mental health related problem among the refugees. Thus hypothesis $\mathrm{V}$ presuming relationship between the perceived trauma and mental health among the refugees was confirmed.

\section{Discussion}

Over all findings indicated that male and female refugees experienced traumatic events in the past which affected their mental health. From the results (table 1) it appeared that the male and female refugees were perceived traumatic experiences to greater extent but there was no significant difference $(\mathrm{U}=379.00$ and $\mathrm{Z}=.708)$ between the male and female refugees on traumatic experiences scores.

But significant differences were found in two age groups of both the genders. The younger refugees scored high on perceived trauma than older refugees in both the genders (table 2\&3). The median of group I (21-35 yrs.) was found 65.00 and IQR was found 11.00 whereas the group II (36-55 yrs.) median was found 57.00 and IQR was 16.25 for the male refugee participants. For the female refugee participants the median of group I (21-35 yrs., $n=14)$ was found 68.00 and IQR was found 18.00 whereas the group II (36-55 yrs.: $\mathrm{n}=9$ ) median was found 56.00 and IQR was found 12.50 .

It can be said that gender variability doesn't play any role in perceiving traumatic events. But the age factor plays crucial role in perceiving traumatic experiences as younger refugees (male $\&$ female) were faced traumatic experiences to larger extent as compare to their counterpart adult or elderly refugees.

Generally, younger refuges reported problems like repeated disturbing memories, thoughts, or images of a stressful experience from the past, feeling of emotionally numb, fear of uniform "super alert", found difficulties in sleeping and night mares, rumination of guilt and feeling of shame. Some of the participants mentioned during the data collection, lack of social support, discrimination and harassments made them feel hopeless and helpless. As the data confirms that traumatic experience perceived by the participants that premises supported by study of Kilpatrick,
Best, Veronen, Amick, Villeponteaux, \& Ruff [5] sampled more than 2000 adult women who had personally experienced such trauma as rape, sexual molestation and aggravated assault. Women who have endured such experiences have an increased vulnerability to further abuse or sexual exploitation in their countries of origin (Allen \& Devitt [16]; Rees [20]).

From the result it appeared that mental health of both male and female refugee participants were affected equally. From the result (table 4) it appeared that there was no significant difference $(U=309.00$ and $Z=1.77)$ were found between the two groups of male and female refugees on mental health. Despite of gender differences mental health related problems affected all refugees' participants. There is no role of gender variability in mental health problems among refugees. But significant differences were found among two groups based on age of participants. The median of group I (21-35 yrs.: $n=11)$ was found 64.00 and IQR was found 6.00 whereas the group II (36-55 yrs., $\mathrm{n}=26$ ) median was found 59.00 and IQR was 3.25 for the male participants. For the female participants the median of group I (21-35 yrs.) was found 58.00 and IQR was found 6.00 whereas the group II (36-55 yrs.) median was found 56.00 and IQR was found 5.50.

Among the refugee's pre-migration conditions like extreme torture, extortion, rape etc. was very stressful resulting in poor mental health and post-migration, social factors such as language, poverty, unemployment, racism and family dysfunction are central to increased risk factors that affect quality of life which make them vulnerable to poor mental health like depression, anxiety, phobia and other disorders. Past epidemiological studies amongst refugees (Lopes Cardozo, Vergara, Agani, \& Gotway, [2]; Modvig, Pagaduan-Lopez, Rodenburg, Salud, Cabigon, \& Panelo, [12]; Mollica, McInnes, Sarajlic, Lavelle, Sarajlic \& Massagli [19]; De Jong, Komproe, Van Ommeren, Masri, Araya, Khaled, Van De Put \& Somasundaram [14] have focused on high prevalence, stress-related disorders, and particularly post-traumatic stress disorder (PTSD) and depression. These studies provide little indication of the needs generated by low prevalence but severe disorders such as psychosis and neuro-psychiatric disturbances (Somasundaram, Van de Put, Eisenbruch, \& De Jong [6]).

Results of the present study indicated that traumatic experiences and mental health problems go side by side. Higher will be the traumatic experiences higher will be the mental health problems. The results presented in table 7 , showed inverse but significant relationship between the two variables namely perceived trauma and mental health $(\rho=.565$. Refugees exposed trauma over a period of time spans and developmental phase suffered from a variety of psychological problems not only the diagnosis of PTSD, including depression, anxiety, self-hatred, dissociation, self-destructive and risk taking behaviours, victimization, problems with interpersonal and intimate relationships medical and somatic concerns. It has been documented that many refugees arrive in asylum countries with particular health and mental health needs. Discrimination is 
increasingly recognized as an adverse mental health risk (Finch, Kolody, \& Vega [1]).

\section{Conclusions}

It can be concluded that gender differences was not found among refugee on perception of traumatic experiences and mental health status. However, age factor was found significant in the perception of traumatic experiences as well as the mental health of Burmese refugees. Further inverse and significant relationship was found between the perception of trauma and mental health status of refugees. It appeared that the continuous exposures of traumatic experiences had serious impact on mental health of refugees and can make them more vulnerable to further abuse in countries of asylum.

\section{REFERENCES}

[1] B. Finch, B. Kolody \& W. Vega. Perceived discrimination and depression among Mexican origin adults in Calif, Journal of Health and Social Behavior, Vol.41, No.3, 295-313, 2000.

[2] B. Lopes Cardozo, A. Vergara, F. Agani, \& C.A. Gotway. Mental health, social functioning, and attitudes of Kosovar Albanians following the war in Kosovo, JAMA, 284, 569-577, 2000.

[3] C. Rousseau, \& A. Drapeau. The impact of culture on the transmission of trauma: Refugees' stories and silence embodied in their children's lives. In Y. Danieli (Ed.), International handbook of multigenerational legacies of trauma (pp. 465-486). New York: Plenum Press, 1998.

[4] D.B. Stern. "Witnessing across time: accessing the present from the past and the past from the present", The Psychoanalytic Quarterly,Vol.81, No.1, 53-81, 2012.

[5] D.G. Kilpatrick, C.L. Best, L.J. Veronen, A.E. Amick, L.A. Villeponteaux, \& G.A Ruff. Mental health correlates of criminal victimization: A random community survey, Journal of Consulting and Clinical Psychology, Vol. 53, 866-873, 1985.

[6] D.J. Somasundaram, W.A. Van De Put, M. Eisenbruch, and J.T. De Jong. Starting mental health services in Cambodia. Social Science \& Medicine, Vo.48, No.8, 1029-1046, 1999.

[7] E. Heptinstall, V. Sethna, \& E. Taylor. PTSD and depression in refugee children: Association with pre-migration trauma and post-migration stress, European Child and Adolescent Psychiatry, Vol.13, 373-380, 2004.

[8] E. Keyes. Mental health status in refugees: An integrative review of current research, Issues in Mental Health Nursing, Vol.21, No.4, 397 - 410, 2000.
[9] F.W. Weathers, B.T. Litz, D.S. Herman, L.A. Huska \& T.M. Keane. The PTSD Checklist (PCL): Reliablity, validity, and diagnostic utility. Paper presented at the 9th Annual Conference of the ISTSS, San Antonio, 1993.

[10] J. Ormel, B.F. Jeronimus, M. Kotov, H. Riese, E.H. Bos \& B. Hankin. "Neuroticism and common mental disorders: Meaning and utility of a complex relationship",Clinical psychology review, Vol.33, No.5, 686-697, 2013.

[11] J.E. Overall, \& D.R. Gorham. "The Breif Psychiatric Rating Scale”, Psychol Rep, Vol.10, 799-812, 1962.

[12] J.J. Modvig, Pagaduan-Lopez, J. Rodenburg, C.M. Salud, R.V. Cabigon, \& C.I. Panelo. Torture and trauma in post-conflict East Timor. The Lancet, 356: p. 1763, 2000.

[13] J.M. Malouff, E.B. Thorsteinsson \& N.S. Schutte. "The relationship between the five factor model of personality and symptoms of clinical disorders", Journal of Psychopathology and Behavioral Assessment, Vol.27, No.2, 101- 114, 2005.

[14] J.T. De Jong, I.H. Komproe, M. Van Ommeren, M. El Masri, M. Araya, N. Khaled, W. van De Put \& D. Somasundaram. Lifetime events and post-traumatic stress disorder in 4 post-conflict settings. JAMA, Vol. 286, 555-652, 2001.

[15] L.L. Halcon, C. Robertson, K. Savik, D.R. Johnson, M.A. Spring, J.N. Butcher, et al. Trauma and coping in Somali and Oromo refugee youth. Journal of Adolescent Health, Vol. 35, $17-25,2004$.

[16] M. Allen\& C. Devitt. 'Intimate Partner Violence and Belief Systems in Liberia', Journal of Interpersonal Violence, Vol. 27, No. 17, 3514-3531, 2012.

[17] M. Lacroix \& C. Sabbah. Posttraumatic psychological distress and resettlement: The need for a different practice in assisting refugee families, Journal of Family Social Work, Vol.14, No.1, 43-53, 2011.

[18] R.F. Mollica, C. Poole, L. Son, C. Murray \& S. Tor. Effects of war trauma on Cambodian refugee adolescents' functional health and mental health status, Journal of the American Academy of Child \& Adolescent Psychiatry, Vol.36, 1098 1106, 1997.

[19] R.F. Mollica, K. McInnes, N. Sarajlic, J. Lavelle, I. Sarajlic, \& M.P. Massagli. Disability associated with psychiatric comorbidity and health status in Bosnian refugees living in Croatia, JAMA, 282, 433-439, 1999.

[20] S. Rees. 'Human Rights and the Significance of Psychosocial and Cultural Issues in Domestic Violence Policy and Intervention for Refugee Women', Australian Journal of Human Rights, Vol. 10, No. 2, 1-19, 2004.

[21] V. Papageorgiou, A. Frangou-Gurunovic, R. Ioradanidour, W. Yule, P. Smith \& P. Vostanis. War trauma and psychopathology in Bosnian refugee children, European Child and Adolescent Psychiatry, Vol.9, 84 -90, 2000.

[22] W.H. Sack, G.N. Clarke \& J. Seeley. Multiple forms of stress in Cambodian adolescent refugees, Child Development, Vol.67, 107-116, 1996. 